\title{
A Public Education
}

\author{
BY SIMON BOXALL
}

The general populace-those who have not been lucky enough to become oceanographers and marine biologists-form the focus of any outreach and public understanding program we undertake. But why should we expend time and energy in educating the public when we have our own students to look after and research to do? A number of my colleagues see any form of public engagement as a bit of a nuisance and not really an important part of our routine work. With some individuals, that is possibly a good thing, but in general, public outreach should be high on everyone's agenda. We need to encourage the best young minds into our science if it is to have a future. The "public" are also the voters who put pressure on politicians to give financial and legislative support to what we do. They have a right, as taxpayers, to know what goes on in our largely publicly funded world.

That's the preaching bit over, but how do we get our science out? The work we do is some of the most exciting and photogenic science around, so the task should be simple. Working with schools-nurturing young minds to enjoy science-is important and will be

Simon Boxall (srb2@noc.soton.ac.uk) is Associate Fellow, University of Southampton, National Oceanography Centre, Southampton, UK. the subject of my next article. Here, I want to focus on the public in general, the people we reach through the media and public events.

The media-television, radio, and print-provide some of the most effective ways of selling our subject. Yet, a number of scientists avoid the limelight probably through a fear of the unknown. Some are happy to talk about their very specific area of research but are not comfortable about going slightly out of their spheres. If they were delivering a keynote talk at the next AGU, or teaching grad students, then I would agree. But, what most scientists forget is that even for topics on the edge of their areas of expertise, they still know and understand more than the people they are communicating with when it comes to outreach. The skill they need is not delivering a one-hour lecture on the subject but rather a two-to-three-minute discussion that gives the key points, and does not assume knowledge of the background science. Sometimes a scientist with a broad understanding, presenting on the edge of the research, can give the clearest public summary.

The media look for input on two levels from scientists-response mode and proactive mode. In the first, we need to respond to events in the news as they unfold: tsunamis, oil spills, new discoveries. These stories need comment and input from scientists, often within the hour. Most of the major oceanographic institutions have press offices that do a fantastic job of covering news stories, but they do rely on input from the science teams. Editors have schedules to keep and they need someone in front of camera, or a few paragraphs of input plus pictures for press, immediately. The Indonesian tsunami in December 2004 was a good example of this type of response.

Up until that point, had someone walked down a beach shouting "tsunami," a third of the population would have wanted to buy one, assuming it was a local delicacy, and another third would have thought it was some form of tropical storm moving slowly their way. Although those living in Japan and Hawaii were well versed in the destructive power of such phenomena, the rest of the world immediately wanted to know what they were and what caused them. Within 24 hours, the true meaning of tsunami was known to most of the world.

News stories have no respect for weekends or sleep, and often a major event runs roughshod over everything else happening. But, working with the media is actually rewarding, once you get past the initial unknowns. What you see on broadcast or hear on radio is often not as formal as many imagine. I have 
given numerous radio interviews in my dressing gown in the early morning from home (radio is a wonderful format for bad hair days), and on TV my top half is always neat in shirt and tie, but my bottom half is sometimes in shorts and deck shoes, having just walked off a ship. For all news stories, one needs to get as much information as possible in advance of the interview, but often only a fraction of the information is ever needed. The key to a good interview is to keep it simple and ensure you get a chance to cover the points you see as important, as well as appreciating the main concerns of the reader or viewer.

In the UK during July and August, we get what is affectionately known as Silly Season. Parliament has gone off for summer, as has big business, so any unlikely news story is ripe for becoming big. Headlines such as "Killer Seaweed Attacks Beaches" and "Flotilla of Plastic Ducks Due Any Day on a Beach Near You" are two good examples. The first was in relation to an increase of sea lettuce (Ulva Lactuca) due to unusual meteorological conditions in the UK and France in summer 2009. A horse had slipped on a mat of the weed and its rider was injured on a beach in France, with some hydrogen sulfide gas being released from the dense matting. Panic in the press ensued and a rapid response to calm the situation was needed. My media

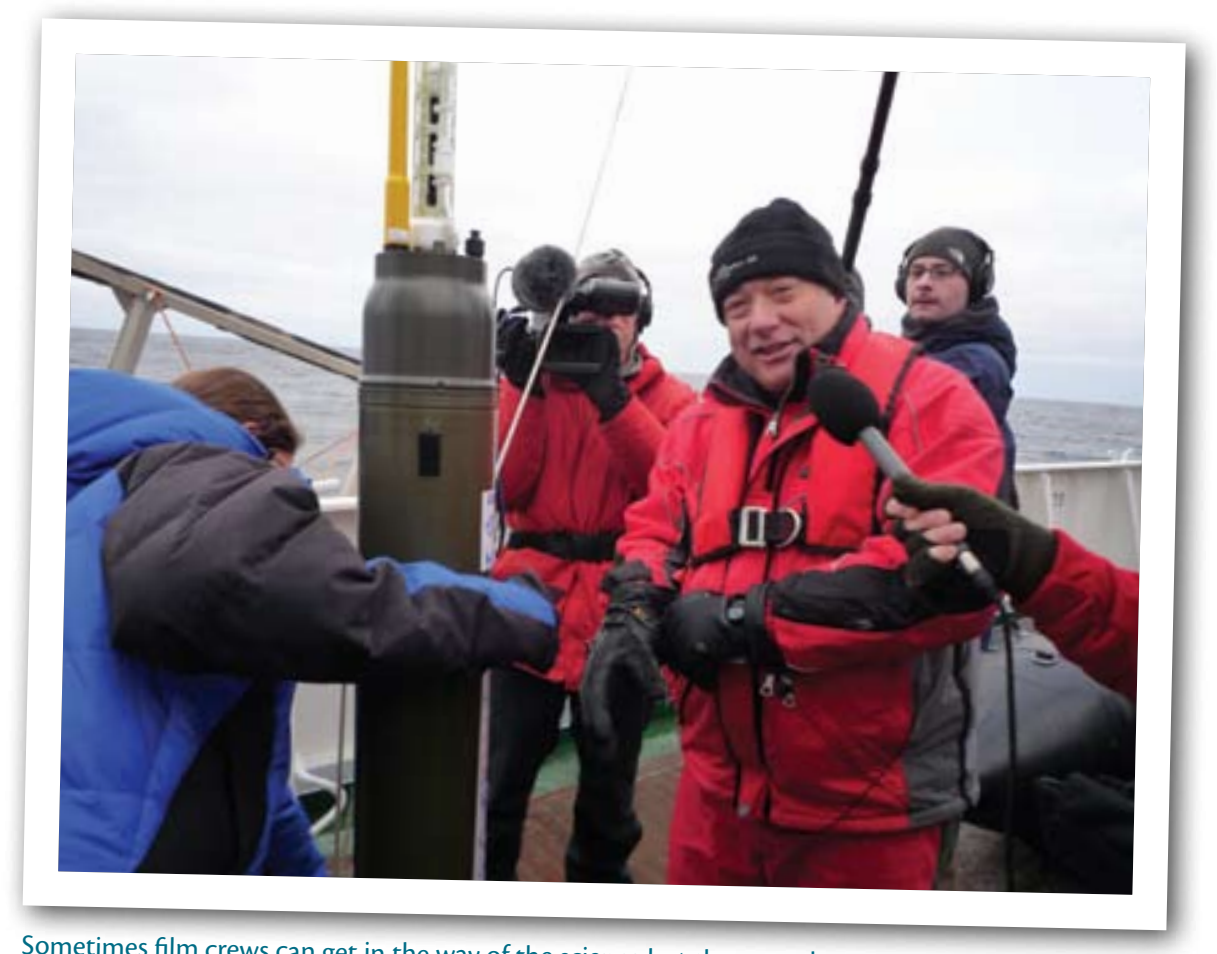

Sometimes film crews can get in the way of the science but the rewards are worthwhile.

faux pas was in taking a handful of sea lettuce straight from the sea and popping it in my mouth to eat it, to show how safe it was, on live TV. As with any experiment being demonstrated to students, try it first. The lettuce sticks to the roof of your mouth and teeth, making you sound and look a complete idiot.

The ducks were from a flotilla spilled off a container in the Pacific in 1992 that Curtis Ebbesmeyer has famously tracked since. It had been suggested that some of these plucky bath toys may have entered the Atlantic 15 years on and could wash up on UK beaches. This story ended up as one of the major ones we have covered over the years, and it was a great way of getting science into the public eye.
I ended up dealing with the story this side of the Atlantic and it got extensive coverage for about a month! What was so good about it was that no one had died and no environmental damage was imminent-it was a feel-good story with a chance to look at ocean circulation. The down side was I now have an office full of yellow ducks. This ending leads neatly into the proactive mode of dealing with the media.

As well as news stories, documentaries and magazine articles are a good ways to promote our science. Here, one has the luxury of more time to plan and ensure a good story line, though this is accompanied by the need for higher quality in the filming and graphics. Three minutes 


\section{HANDS-ON \\ OCEANOGRAPHY}

www.tos.org/hands-on
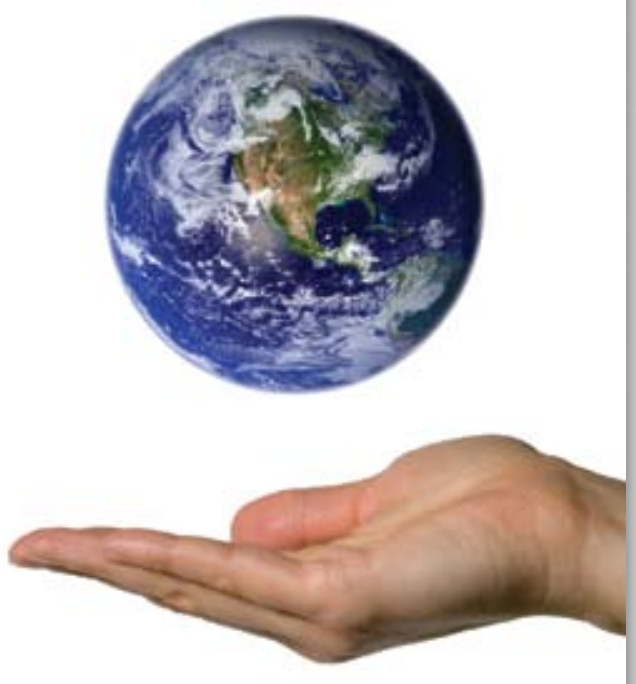

Hands-On Oceanography provides an opportunity for you to publish teaching materials developed for undergraduate and/or graduate classes in oceanography. Activities include, but are not limited to, computerbased models and laboratory demonstrations that actively engage students (i.e., activities where students have to make decisions, record results, and interpret results). All submissions are peer reviewed. Publication of teaching materials may address the broader impacts criterion for NSF-funded research.

Visit www.tos.org/hands-on to download published activities or for more information on submitting an activity of your own for consideration. of news takes about half an hour of setup and recording/live broadcast. The same footage of documentary takes over half a day of recording and extensive postproduction work. The other big issue with documentaries is that a significant amount of oceanography happens at sea, which involves film crews on board. This option is not always popular, when space for scientists is in short supply. It needs projects like Cape Farewell (http://www.capefarewell.com), where the main aim of the research cruise is public understanding and film making. Some organizations equip their scientists with cameras and training, and these efforts have produced some good output, though professional film crews are noticeably better.

The media can cover a large proportion of the population, but public events where our work is on show or we deliver public lectures are as important even though they address a smaller audience. A documentary will reach up to 80 million people, our open day in Southampton about 2,500, a talk at a science café less than 100, for example, but here the interaction is more intense. This performance is live and on stage, and the viewers interact! Often, a more informed public attends these events, some from other science areas, and the material delivered is much more detailed. The audiences are usually more questioning than our own students and we need to be well within the subject area. Some of the most pertinent questions on my own subject areas have arisen in public lectures. These questions are often not easy to answer, particularly when the tools available for the speaker to use to explain the science are limited in this arena. However, the rewards are high, with students being recruited and the occasional local politician being in the audience.

Public lectures also expose one to the shallow end of the human gene pool. Every so often you will come across the misguided amateur scientist. My two favorites were the solution to the ozone hole, and the solution to world power production (wow!). The first involved letting $10 \%$ of the air out of car tires to top up the ozone layer, and the second fitting turbines to our Argo floats and transmitting the power back via satellite. We need to keep that dialog with our public going to counter these "unusual" views as well as to recruit young scientists. 可 